\title{
TRENDS IN DRUG CONSUMPTION AND RISK OF TRANSMISSION OF HIV AND HEPATITIS C VIRUS AMONG INJECTING DRUG USERS IN SWITZERLAND, $1993-2006$
}

\author{
F Dubois-Arber (Francoise.Dubois-Arber@chuv.ch) ${ }^{1}$, H Balthasar ${ }^{1}$, T Huissoud ${ }^{1}$, F Zobel ${ }^{1,2}$, S Arnaud $^{1}$, S Samitca $^{1,3}$, \\ A Jeannin ${ }^{1}$, D Schnoz ${ }^{4}$, J P Gervasoni ${ }^{1}$ \\ 1. Institute of Social and Preventive Medicine (IUMSP), University Hospital Centre and University of Lausanne, Switzerland \\ 2. European Monitoring Centre for Drugs and Drug Addiction (EMCDDA), Lisbon, Portugal \\ 3. Instituto de Ciências Sociais, Universidade de Lisboa, Portugal \\ 4. Institut für Sucht und Gesundheitsforschung, Zürich, Switzerland
}

As a part of the HIV behavioural surveillance system in Switzerland, repeated cross-sectional surveys were conducted in 1993, 1994, 1996, 2000 and 2006 among attenders of all low threshold facilities (LTFs) with needle exchange programmes and/or supervised drug consumption rooms for injection or inhalation in Switzerland. Data were collected in each LTF over five consecutive days, using a questionnaire that was partly completed by an interviewer and partly self administered. The questionnaire was structured around three topics: socio-demographic characteristics, drug consumption, health and risk/preventive behaviour. Analysis was restricted to attenders who had injected drugs during their lifetime (IDUs). Between 1993 and 2006, the median age of IDUs rose by 10 years. IDUs are severely marginalised and their social situation has improved little. The borrowing of used injection equipment (syringe or needle already used by other person) in the last six months decreased $(16.5 \%$ in $1993,8.9 \%$ in 2006$)$ but stayed stable at around $10 \%$ over the past three surveys. Other risk behaviour, such as sharing spoons, cotton or water, was reported more frequently, although also showed a decreasing trend. The reported prevalence of HIV remained fairly stable at around 10\% between 1993 and 2006; reported levels of hepatitis C virus (HCV) prevalence were high (56.4\% in 2006). In conclusion, the overall decrease in the practice of injection has reduced the potential for transmission of infections. However as HCV prevalence is high this is of particular concern, as the current behaviour of IDUs indicates a potential for further spreading of the infection. Another noteworthy trend is the significant decrease in condom use in the case of paid sex.

\section{Introduction}

Drug consumption, especially by injecting drug use, is a significant problem in Switzerland which culminated in the early 1990s with open drug scenes. Switzerland also had the highest rate of newly diagnosed HIV infections in Europe in the late 1980s [1]. The HIV epidemic is concentrated in IDUs and men having sex with men with estimated prevalences of more than $5 \%$. Many harm reduction services and treatment options for IDUs have been progressively developed in Switzerland since the 1980s in response to the HIV/AIDS epidemic:

- Low threshold facilities (LTFs), characterised by easy access, anonymity and no treatment offered, with needle exchange programmes including or not supervised drug consumption rooms for injection or inhalation;

- Permission for sale of injection equipment in pharmacies; and
- Vaccination programmes against hepatitis $B$, methadone substitution/maintenance treatment, and treatments with medically prescribed heroin [2].

Within the framework of both the evaluation of the Swiss government measures - introduced in 1991 - to reduce drug-related problems [2] and the evaluation of the Swiss HIV/AIDS prevention policy [1], five successive national surveys of LTF attenders [3] were conducted, in 1993, 1994, 1996, 2000 and 2006. In this way, a behavioural surveillance system was established among LTF attenders who had injected drugs in their lifetime (named here IDUs) [4]. The decision to concentrate on this group in LTFs reflects the intention to follow up on trends regarding the possible transition from injecting to non-injecting drug use. As all LTFs offering inhalation rooms were included, it is possible to find in these locations injectors currently not injecting but still consuming drugs by inhalation. This article presents the evolution over time of the main indicators included in this system.

\section{Methods}

Behavioural surveillance among IDUs is based on a periodic survey of LTFs, using a questionnaire in German or French, proposed to all users of the facility during five consecutive days. Each LTF was eligible for the survey. However, participation varied over time, the number of LTFs included increased: 13 in 1993 , 15 in 1994, 16 in 1996, 23 in 2000 and 22 in 2006. In 1993, 1994 and 2000, the three LTFs based in the canton of Zurich did not participate, while local studies were being conducted over the same period. In 2000, Zurich provided data from a local study using most of our indicators. In 2006, the LTFs were located in 10 cantons; half of these included a supervised drug consumption room for injection or inhalation.

Each survey was conducted at the same period of the year, at the end of the first semester (May, June) except for 1996 (autumn). Over five consecutive days, two specially trained interviewers asked all LTF attenders to answer an anonymised questionnaire.

The questionnaire was structured according to three topics:

- Socio-demographic characteristics;

- Drug consumption: frequency of heroin and cocaine use during the previous month, injection during the previous six months and the last month, number of injections in the last week, current substitution treatment; and 
- Health and risk/protection behaviour: perceived health, HIV testing and results, hepatitis $B$ and $C$ testing and results, borrowing of injection material (injecting with a syringe/needle already used another person) during the previous six months and the last month, condom use during the previous six months with occasional sexual partners, steady partner(s), or clients in case of paid sex.

The first part of the questionnaire, including socio-demographic characteristics, drug consumption and injection practice was undertaken via a face-to-face interview; the second part, including questions on sharing of injection material, sexual behaviour and condom use, and social integration, was self-administered or undertaken face-to-face if the respondent so wished. The last part, on health status, including testing history and HIV/HCV status, was self-administered and there was no control over the completion of this part by the interviewer.

Questionnaires declared as unreliable by the interviewers usually questionnaires with many inconsistencies - were excluded from the analysis (32 in 2006). The number and characteristics of non-participants (sex, estimated age, reason for refusal) were documented by the interviewers, except in 1993.

Bivariate analysis used Pearson's chi-square test and trend analysis was conducted on annual aggregated data. Trend significance was assessed using the nptrend test (nonparametric test) available on Stata.

\section{Results}

\section{Participation and selection}

The participation rate of LTF attenders was $76 \%$ in $1994,81 \%$ in $1996,69 \%$ in 2000 , and $66 \%$ in 2006 . It varied across cantons (from $45 \%$ to $79 \%$ ) and was lower when the LTF was a mobile unit (bus), which only distributed material. The surveys included 1,119 individuals in 1993, 764 in 1994, 944 in 1996, 924 in 2000, 1,083 in 2006. Participants and non-participants did not differ according to age and sex.

The analyses presented were restricted to IDUs having ever injected drugs, as defined above: 993 in 1993, 677 in 1994, 855 in 1996, 832 in 2000, and 817 in 2006. This selection represents about $90 \%$ of 1993 to 2000 respondents and $75 \%$ of the 2006 sample.

Socio-demographic characteristics of IDUs

Around three quarters of the IDUs are men. This proportion remained stable over time. The median age in all IDUs increased significantly, from 26 years in 1993 to 36 in $2006(p<0.01)$ and the proportion of IDUs aged 25 years or younger decreased from $39.3 \%$ in 1996 to $7.5 \%$ in 2006 . This trend is observed in both sexes. A stable proportion of one third of IDUs completed compulsory schooling. Employment during the last month, part- or full-time, decreased over time, from $44.8 \%$ in 1993 to $36.8 \%$ in 2006 ( $p<0.01$ ); over the same period, people receiving revenue from social insurance such as disability pension or unemployment benefit or from social assistance increased from 8.8\% in 1993 to $35.4 \%$ in 2006 , respectively $27.8 \%$ to $45.0 \%$ ( $p<0.01$ for both situations). The proportion of IDUs living without fixed abode during the last month decreased from $11.4 \%$ in 1993 to $6.2 \%$ in $2006(p<.01)$

\section{Consumption}

Almost all IDUs, have consumed heroin (98\%) or cocaine $(95.5 \%)$ in their life. However, current consumption (in the last month) changed over time: for heroin from $60.5 \%$ in 93 to $43.1 \%$ in 2006 and for cocaine from $23.7 \%$ in 1993 to $63.5 \%$ in 2006 (for both cases, $\mathrm{p}<0.01$ ). Furthermore the proportion of IDUs on methadone treatment among IDUs in LTFs increased from $37.2 \%$ in 1993 to $59.1 \%$ in $2006 ; 5.1 \%$ are on medically supervised heroin treatment (11.2\% in 1996).

About half of the IDUs reported having ever had an overdose (52.3\% in 1996, 48.2\% in 2000, 54.7\% in 2006, $p=0.240$.)

Injection practice and risk exposure

Current injection practice is decreasing: $95.1 \%$ of IDUs had injected during the past six months in 1993 versus $74.2 \%$ in 2006 (see Table 1). The proportion of "new injectors" having begun to inject in the last two years, is also decreasing: from 18.7\% in 1993 to $3.3 \%$ in 2006 .

For current injectors, the median number of injections performed in the last week by was halved between 1996 and 2006, from 14 to 7 . Most injections took place at home (56.4\% in 2006) or in a supervised drug consumption room (32.8\% in 2006).

Almost half of IDUs have borrowed used injection equipment (syringe/needle) at least once during their lives, and almost one in ten did so in the past six months. This proportion has been quite stable since 1994, after a decrease between 1993 and 1994. Sharing of other injection paraphernalia such as spoons, filters and water, is more common, although on the decrease since 1996 (except for cotton sharing). In 2006, 23.4\% reported having had an abscess in relation with injection in the past six months.

\section{Sexual risks}

In 2006, about half of the IDUs had sexual intercourse with a steady partner in the past six months $(56.9 \%$ in $1993,54.4 \%$ in $1994,50.8 \%$ in $1996,54.5 \%$ in $2000,51.9 \%$ in $2006, p=.127$ ) and less than $30 \%$ of them systematically used condoms $(25.5$ in $1993,25.5$ in $1994,26.7 \%$ in $1996,28 \%$ in $2000,28.5 \%$ in $2006, p=0.211$ ). About $30 \%$ reported sexual intercourse with occasional partner(s) in the past six months $(31.8 \%$ in 1993 , $28.4 \%$ in $1994,30.9 \%$ in $1996,31.4 \%$ in $2000,27.3 \%$ in $2006, p=0.122)$, the proportion of those declaring systematically using condoms in this situation increased $(59.5 \%$ in $1993,70.8 \%$ in $1994,64.4 \%$ in $1996,71.1 \%$ in $2000,71.8 \%$ in 2006 , $\mathrm{p}<0.01)$.

The proportion of women reporting paid sex in the past six months remained stable $(16.4 \%$ in $1993,23.7 \%$ in $1996,18.9 \%$ in $2000,19.8 \%$ in $2006, p=0.98$.) and condom use with clients decreased significantly $(90.0 \%$ in $1994,94.4 \%$ in $1996,74.4 \%$ in $2000,81.4 \%$ in $2006, p=0.030)$.

\section{HIV/HCV testing}

Over $90 \%$ IDUs have already had an HIV test (see Table 2). In 2006, 62.4\% had been tested during the past two calendar years. The reported HIV prevalence among those tested remained stable between 1993 and 2006 at about 10\% (lowest value $8.8 \%$ in 1994, highest $11.4 \%$ in 1996 and 2000, $p=0.560$ ). In $2006,71.8 \%$ of persons tested HIV positive were on antiretroviral treatment. 
T A B L E 1

Injection practice and risk exposure (in \%) among injecting drug users*, Switzerland , 1993-2006 (n=4,174)

\begin{tabular}{|c|c|c|c|c|c|c|}
\hline & $1993^{* *}$ & $1994^{* *}$ & 1996 & 2000 & 2006 & nptrend ; $p=$ \\
\hline N & 993 & 677 & 855 & 832 & 817 & \\
\hline \multicolumn{7}{|l|}{ Injection } \\
\hline Injection in the last 6 months & 95.1 & 95.1 & 95.0 & 86.8 & 74.2 & $p<0.01^{+}$ \\
\hline New injectors ${ }^{\star \star \star}$ & 18.7 & 16.4 & 7.4 & 3.2 & 3.3 & $p<0.01^{+}$ \\
\hline Median number of years injecting & 6 & 7 & 9 & 12 & 15 & $* \star \star * *<<0.01^{+}$ \\
\hline $\begin{array}{l}\text { Median number of injections in the last week (among the last } \\
6 \text { months injectors) }\end{array}$ & - & - & 14 & 7 & 7 & 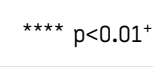 \\
\hline Most frequent place for injecting & & & & & & $p<0.01^{+}$ \\
\hline Private place & - & 47.4 & 58.4 & 60.7 & 56.4 & \\
\hline Public place outdoors & - & 18.2 & 5.5 & 6.0 & 3.1 & \\
\hline Public place indoors & - & 2.6 & 3.0 & 3.4 & 2.0 & \\
\hline Supervised drug consumption room & - & 29.8 & 28.6 & 24.4 & 32.8 & \\
\hline Non response & - & 2.0 & 4.6 & 5.5 & 5.6 & \\
\hline \multicolumn{7}{|l|}{ Risk exposure } \\
\hline Ever borrowed used equipment ${ }^{\star \star \star \star \star}$ & 39.1 & 37.1 & 43.3 & 44.6 & 42.7 & $0.029^{+}$ \\
\hline $\begin{array}{l}\text { Borrowed in the last } 6 \text { months }{ }^{* \star * * *} \text { (among the last } 6 \text { months } \\
\text { injectors) }\end{array}$ & 16.5 & 8.9 & 10.7 & 11.5 & 8.9 & $p<0.01^{+}$ \\
\hline Borrowed in the last month (among the last month injectors) & & & & & 4.9 & \\
\hline Lended equipment in the last 6 months & & 9.2 & 9.4 & 8.6 & 7.8 & 0.308 \\
\hline \multicolumn{7}{|l|}{$\begin{array}{l}\text { Sharing of material serving to prepare the injection in the } \\
\text { last } 6 \text { months (among the last } 6 \text { months injectors) }\end{array}$} \\
\hline Spoon & - & - & 67.1 & 49.9 & 31.9 & $p<0.01^{+}$ \\
\hline Filter & - & - & 42.5 & 36.2 & 21.1 & $p<0.01^{+}$ \\
\hline Cotton & - & - & 3.1 & 6.1 & 2.0 & 0.115 \\
\hline Water & - & - & - & 24.6 & 15.8 & $p<0.01^{+}$ \\
\hline
\end{tabular}

* $\quad p<=0,05$ significant (statistical significance of trends after exclusion of missing data)

** participants who had injected drugs during their lifetime

** Zurich not included

***$\quad \%$ of persons having begun injecting in the last 2 years

$* * \star * \quad$ Pearson chi-square

$\star \star \star \star \star \quad$ Syringe or needle already used by other person

italics : no data available from Zurich in 2000

In $2006,88.4 \%$ had ever been tested for hepatitis C, $58 \%$ of them during the past two calendar years; reported prevalence of HCV was $56.4 \%$, out of those $16.7 \%$ were currently on treatment.

Persons tested positive for HCV were compared to those HCV negative or untested (see Table 3). HCV-positive IDUs were older, more likely to be HIV-positive and more often declared a bad or quite bad health status. They were also more likely to be active injectors than untested or HCV-negative persons. The proportion of "borrowers" in the past six months among HCV was not significantly different from that of the other group, although a higher proportion of them had shared material serving to prepare injection. However, they were more likely to have used a condom at last intercourse.

\section{Discussion}

Switzerland is one of the Western European countries, along with France [5,6], Italy [7], Germany, the Netherlands (cohort data) [8], Spain [9], and the UK [10,11], where surveys or other types of data collection on behaviour in IDUs have been conducted repeatedly. Recruitment in LTFs allows us to reach a particularly vulnerable and marginalized population of IDUs. A study on hardto-reach IDUs conducted in Switzerland showed that the majority do attend LTFs [12].

However, our study has limitations. The type of clients attending LTFs may vary in the course of the day (there was no data collection in 1996 and 2000 in the evening or during week-ends) or over the year. Services offered and opening hours can vary across the LTFs and from year to year. Attendance and participation varied between surveys: the proportion of participants contributed by each town differed from survey to survey. The conditions surrounding the completion of the questionnaire are difficult per se (stress in the premises, persons under the influence of drugs or withdrawal symptoms) and are difficult to maintain strictly stable (degree of quietness in the premises, proportion of persons preferring to complete the second part of the questionnaire with the interviewer, etc.). Furthermore, LTF attenders may not be representative of all IDUs in the towns surveyed: migrant IDUs insufficiently proficient in 
T A B L E 2

HIV and hepatitis C testing performed and HIV / hepatitis C reported prevalence among injecting drug users* (in \%), Switzerland, 1993-2006 $(\mathrm{n}=4,174)$

\begin{tabular}{|c|c|c|c|c|c|c|}
\hline & 1993 & 1994 & 1996 & 2000 & 2006 & nptrend ; $p=$ \\
\hline N & 993 & 677 & 855 & 832 & 817 & \\
\hline Ever been tested for HIV & 90.2 & 92.5 & 93.7 & 96.2 & 95.8 & $p<0.01^{+}$ \\
\hline HIV status at last test & & & & & & 0.560 \\
\hline HIV positive & 10.8 & 8.8 & 11.4 & 11.4 & 10.9 & \\
\hline HIV negative & 87.2 & 89.3 & 86.5 & 86.5 & 87.0 & \\
\hline non response / unknown & 2.0 & 1.9 & 2.2 & 2.1 & 2.2 & \\
\hline Ever been tested for HCV & - & - & - & 79.8 & 88.4 & ${ }^{\star \star \star} p<0.01^{+}$ \\
\hline HCV status at last test & & & & & & *** 0.064 \\
\hline HCV positive & - & - & - & 61.5 & 56.4 & \\
\hline HCV negative & - & - & - & 34.3 & 40.4 & \\
\hline non response / unknown & - & - & - & 4.2 & 3.2 & \\
\hline
\end{tabular}

$+p<=0,05$ significant

* participants who had injected drugs during their lifetime

** $\quad$ Zurich not included

*** Zurich not included

italics : no available data from Zurich in 2000

TA B L E 3

Characteristics of hepatitis C positive intravenous drug users versus others (in \%), Switzerland, $2006(\mathrm{n}=817)$

\begin{tabular}{|c|c|c|c|}
\hline & $\begin{array}{r}\text { Not tested or VHC- } \\
\text { negative }\end{array}$ & VHC-positive & $\begin{array}{r}\text { Chi-square } \\
P=\end{array}$ \\
\hline $\mathrm{N}$ & 410 & 407 & \\
\hline Female & 25.6 & 28.4 & 0.371 \\
\hline 35 years old and more & 52.3 & 65.4 & $\mathrm{p}<0.01^{+}$ \\
\hline Unemployed last month & 61.5 & 64.9 & 0.314 \\
\hline Education: compulsory school & 27.2 & 33.3 & 0.058 \\
\hline Private housing last month & 84.9 & 85.8 & 0.725 \\
\hline Injected last week & 56.8 & 66.3 & $0.005^{+}$ \\
\hline Borrowed in the last 6 months & 7.1 & 10.5 & 0.150 \\
\hline \multicolumn{4}{|c|}{ Sharing of material serving to prepare the injection in the last 6 months } \\
\hline spoon & 27.1 & 36.8 & 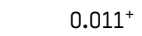 \\
\hline filter & 17.8 & 24.8 & $0.040^{+}$ \\
\hline cotton & 3 & 1.2 & 0.137 \\
\hline water & 13.7 & 18.3 & 0.133 \\
\hline Used condom at last intercourse & 46.9 & 54.2 & $0.041^{+}$ \\
\hline HIV status & & & $p<0.01^{+}$ \\
\hline non tested & 6.2 & 0.7 & \\
\hline HIV-positive & 7.2 & 13.8 & \\
\hline HIV -negative & 84.6 & 83.2 & \\
\hline Self evaluated health status / bad, rather bad & 20 & 30.9 & 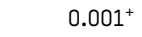 \\
\hline
\end{tabular}

$+p<=0,05$ significant 
the two languages of the questionnaire (French and German) were not included as for example in Geneva in 2006 with a group of young eastern European migrant IDUs. The survey does not include IDUs living in smaller cities without LTFs, and the results may therefore not be representative of all IDUs in Switzerland. In spite of these limitations, the type of recruitment in all Swiss LTFs over the same time and period of the year and with the same procedures provides a reasonable approximation of a national representative sample of all attenders of this type of structure.

Over a 13-year period (1993-2006), the average age of IDUs rose by 10 years; there are increasingly fewer young and new IDUs in LTFs. This may be for several reasons: a change in the type of consumption which would delay the transition to intravenous (i.v.) drug use and attendance of LTFs, a decrease in the capacity of LTFs to attract young IDUs, an increase in the number of IDUs entering treatment early in their drug consuming career, or a true decrease in the number of persons having ever consumed heroine or cocaine by injection.

It seems unlikely, however, that this trend is due to limited access to LTFs among juveniles or new users, since a Swiss study of drug users not in treatment, recruited at home or in public places, showed that following their transition to i.v. drug use, they rapidly made contact with an LTF [13]. There has been an increase in the number of persons entering methadone substitution treatments over the period, although without decrease in the average age at entry (see below). A real fall in the number of new IDUs is however highly probable since ageing has also been observed among other populations of IDUs: during the same period the average age of persons entering methadone outpatient treatment, residential treatment and heroin substitution treatment rose in Switzerland $[2,14,15]$.

IDUs attending LTFs tend to be severely marginalised and their social situation has shown little improvement. Even if the percentage of homeless IDUs has decreased, the rates of unemployment and of IDUs receiving social benefits have increased.

Types of drug consumed and mode of consumption show significant changes over time: heroin consumption decreased along with an increase in cocaine consumption whereas i.v. drug use, the proportion of new injectors and the number of injections in the past week among injectors decreased sharply. Similar trends have been observed in Catalonia, Spain [9] and in several European countries [16]. However, there are differences between cities: e.g. in Geneva new populations of injectors, younger, heroin consuming, some of them migrants, are appearing [17].

Although over half of IDUs attending LTFs are undergoing substitution treatment, they probably represent a minority of all persons in treatment: about 17,000 in 2005 for the whole of Switzerland [18]. Swiss methadone treatment policy has evolved towards a variety of approaches differing according to individual needs and including maintenance. In this case, persistence of consumption is generally not a reason to exclude patients [19]. An unknown proportion of these patients, still consuming drugs such as heroin or cocaine, also visit LTFs.

Trends in indicators of risk exposure regarding HIV or HCV differ: the borrowing of used equipment in the last six months still exists in a minority of current IDUs, the proportion of those doing so remaining rather stable around $10 \%$ in the last three surveys, being one of the lowest rates reported in Europe. For example, sharing ie. passing on or borrowing used syringe or needle in the last month was between $28 \%$ to $39 \%$ in England in 2000 [20], 13\% of IDUs declared having borrowed equipment in the last month in France in 2004 [8] and between $15.6 \%$ and $19.8 \%$ in the past six months in Barcelona in 2005 [9].

Sharing of material serving to prepare injection remains higher, although decreasing. This practice is of particular concern in regards to HCV: sharing paraphernalia is an important route for $\mathrm{HCV}$ transmission and reported prevalence of HCV infection is high among IDUs and a high percentage of HCV-positive IDUs share this type of material with other IDUs (Table 3 ).

A relative stability is observed regarding sexual risk exposure and protection. About one quarter of the IDUs report systematic condom use with steady partners, and more than two-thirds with occasional partners, a level of protection comparable to that observed in the general population [21]. A significant decrease in protection through the use of condoms in the case of paid sex is nevertheless reported.

Most IDUs have undergone HIV testing and the reported prevalence remained stable over time at about $10 \%$.

HCV testing seems to be increasing and levels of reported HCV prevalence are high. Since the beginning of the nineties prevalences between $13 \%$ and $80 \%$ in IDUs have been reported in Switzerland [3]. Reported HCV prevalence is probably underestimating true prevalence, as it was demonstrated in France [6]; on the other hand, reported HIV prevalence was more similar to biological prevalence.

High levels of hepatitis $C$ seroprevalence, with lower or decreasing HIV prevalence among drug users have also been observed in many countries: France [22], England [23], Italy [24], Norway [25], European Union in general [26, 27], Canada [28], USA [29], Australia [30].

\section{Conclusions}

In conclusion, the overall decrease in i.v. drug use in Switzerland has reduced the potential for transmission of HIV and HCV, in spite of the persistence of injection material sharing by a minority of IDUs. Newly diagnosed HIV infections in IDUs notified in Switzerland decreased sharply during the 1990s. This decrease continued in recent years with a stabilisation in 2006 and 2007 (respectively 60 and 61 new cases)[31]. However, the epidemiological situation needs to be monitored carefully since a new increase in heroin consumption and i.v. injection is possible with the increase in production observed in recent years [16].

To address some of the short comings from our survey, other methods of data collection for behavioural surveillance (including collection of biological samples) may be considered, in particular methods including a recruitment extending outside LTFs - such as respondent driven sampling - in order to explore the existence of populations of injectors, especially young ones, possibly not using LTFs. Furthermore, to better take into account the fact that part of their clientele is on substitution treatment, LTFs should consider new ways of linking with treatment centres. Special attention needs to be paid regarding HCV. The reported prevalence is high and current behaviours of HCV infected IDUs, in particular the sharing of material serving to prepare injection, suggest a potential for further spreading of the infection. 


\section{Acknowledgements}

The study was funded by the Federal Office of Public Health, Berne, Switzerland. Contract number: 04.000158 / 2.24.01.-744

Some of the data presented here have been presented in the Bulletin of the Federal Office of Public Health. Balthasar H, Huissoud T, Zobel F, Arnaud S, Samitca S, Jeannin A, Schnoz D, Gervasoni JPG, Dubois-Arber F. Evolution de la consommation et des pratiques à risques de transmission du VIH et du VHC chez les consommateurs de drogue par injection en Suisse, 1993-2006. Bulletin OFSP 2007;45:804-9.

\section{References}

1. Dubois-Arber F, Jeannin A, Spencer B. Long term global evaluation of a national AIDS prevention strategy: the case of Switzerland. AIDS 1999;13:2571-82.

2. Zobel F, Thomas R, Arnaud S, De Preux E, Ramstein T, Spencer B, et al. Evaluation of the Confederation's measures to reduce drug-related problems: Fourth synthesis report 1999-2002. Lausanne: Institut universitaire de médecine sociale et préventive; 2003. Available from: www.iumsp.ch

3. Benninghoff F, Morency P, Geense R, Huissoud T, Dubois-Arber F. Health trends among drug users attending needle exchange programmes in Switzerland (1994 to 2000). AIDS Care 2006;18(4):371-5.

4. Dubois-Arber F, Jeannin A, Meystre-Agustoni G. Un système de surveillance de deuxième génération pour améliorer la surveillance du VIH/sida en Suisse. Bulletin OFSP 2006;15:277-81.

5. Emmanuelli J, Desenclos JC. Harm reduction interventions, behaviours and associated health outcomes in France, 1996-2003. Addiction 2005;100:1690700.

6. Jauffret-Roustide M, Couturier E, Le Strat Y, Barin F, Emmanuelli J, Semaille C, et al. Estimation de la séroprévalence du VIH et du VHC et profils des usagers de drogues en France, étude InVS-ANRS Coquelicot, 2004. Bull Epidemiol Hebdo 2006;33:244-7.

7. Sabbatini A, Carulli B, Villa M, Correa Leite ML, Nicolosi A. Recent trends in the HIV epidemic among injecting drug users in Northern Italy, 1993-1999. AIDS 2001;15(16):2181-5.

8. Van Ameijden EJ, Langendam MW, Notenboom J, Coutinho RA. Continuing injecting risk behaviour: results from the Amsterdam Cohort Study of drug users. Addiction 1999;94(7):1051-61.

9. SIVES 2005: integrated AIDS/HIV/STI surveillance system of Catalonia, CEESCAT annual report. Barcelona: Generalitat de Catalunya, Departament de Salut; 2006. (Technical document $\mathrm{N}^{\circ} 18$ ).

10. Hope VD, Judd A, Hickman M, Sutton A, Stimson GV, Parry JV, et al. HIV prevalence among injecting drug users in England and Wales 1990 to 2003: evidence for increased transmission in recent years. AIDS 2005;19(11):1207-14.

11. Judd A, Hunter GM, Maconochie N, Hickman M, Parry JV, Renton AM, et al. HIV prevalence and risk behaviour among female injecting drug users in London, 1990 to 1996. AIDS 1999;13(7):833-7.

12. Hausser D, Kübler D, Dubois-Arber F. Characteristics of heroin and cocaine users unknown to treatment agencies: Results from the Swiss hidden population study. Sozial- und Praeventivmedizin 1999;44(5):222-32.

13. Kübler D, Hausser D. Consomateurs d'héroïne et/ou de cocaïne hors traitement médical: étude exploratoire auprès d'une population cachée. Lausanne: Institut universitaire de médecine sociale et préventive; 1996. (Cah Rech Doc IUMSP, no. 111.7).

14. Gervasoni J-P, Zobel F, Kellerhals C, Dubois-Arber F, Spencer B, Jeannin A et al. Evaluation of the Confederation's measures to reduce drug-related problems: third synthesis report 1997-1999. Lausanne: Institut universitaire de médecine sociale et préventive; 2000. Available from: www.iumsp.ch

15. Schorr D, Künzi U. Was sagt uns die methadonstatistik über die Entwicklung der letzten Jahre? Ein Vergleich zwischen ausgewählten Kantonen [What do the methadone statistics tell us about developments over the last few years?]. Abhängigkeiten 2007;(3)

16. European Monitoring Centre for Drugs and Drug Addiction. Annual report 2007: the state of the drugs problem in Europe. Luxembourg: Office for Official Publications of the European Communities; 2007.

17. Huissoud T, Balthasar H, Jeannin A, Samitca S, Dubois-Arber F. Evaluation des activités de prévention du VIH/sida dans le canton de Genève, période 2006. 134 ed. Lausanne: Institut universitaire de médecine sociale et préventive; 2007. (Raisons de santé 134).

18. Schorr D, Künzi U. Was sagt uns die methadonstatistik über die Entwicklung der letzten Jahre? Ein Vergleich zwischen ausgewählten Kantonen [What do the methadone statistics tell us about developments over the last few years?]. Abhängigkeiten 2007;(3): 22-31.
19. Van Ameijden EJC, van den Hoek JAR, Coutinho RA. Injecting risk behavior among drug users in Amsterdam, 1986 to 1992, and its relationship to AIDS prevention programs. Am J Public Health 1994;84(2):275-81.

20. Hope VD, Rogers PA, Jordan L, Paine T, Barnett S, Parry J, et al. Sustained increase in the sharing of needles and syringes among drug users in England and Wales. AIDS 2002;16(18):2494-6.

21. Dubois-Arber F, Jeannin A, Meystre-Agustoni G, Spencer B, Moreau-Gruet $\mathrm{F}$, Balthasar $\mathrm{H}$, et al. Evaluation of the HIV/AIDS prevention strategy in Switzerland: Abridged version of the seventh synthesis report 1999-2003. Lausanne: Institut universitaire de médecine sociale et préventive; 2003. Available from: www.iumsp.ch

22. Valenciano M, Emmanuelli J, Lert F. Unsafe injecting practices among attendees of syringe exchange programmes in France. Addiction 2001;96(4):597-606.

23. Hope VD, Judd A, Hickman M, Lamagni T, Hunter G, Stimson GV, et al. Prevalence of hepatitis $C$ among injection drug users in England and Wales: is harm reduction working? Am J Public Health 2001;91(1):38-42.

24. Quaglio GL, Lugoboni F, Pajusco B, Sarti M, Talamini P, Des Jarlais DC. Hepatitis C infection: prevalence, predictor variables and prevention opportunities among drug users in Italy. J Viral Hepat 2003;10(5):394-400.

25. Miller M, Mella I, Moi H, Eskild A. HIV and Hepatitis $C$ virus risk in new and longer-term injecting drug users in Oslo, Norway. J Acquir Immune Defic Syndr 2003;33:373-9.

26. Roy K, Hay G, Andragetti R, Taylor A, Goldberg D, Wiessing L. Monitoring hepatitis $C$ virus infection among injecting drug users in the European Union: a review of the literature. Epidemiol Infect 2002;129(3):577-85.

27. Matheï C, Buntinx F, Van Damme P. Seroprevalence of hepatitis $C$ markers among intravenous drug users in western European countries: a systematic review. J Viral Hepat 2002;9:157-73.

28. Strathdee SA, Patrick DM, Currie SL, Cornelisse PG, Rekart ML, Montaner JS, et al. Needle exchange is not enough: lessons from the Vancouver injecting drug use study. AIDS 1997;11(8):F59-F65.

29. Diaz T, Des Jarlais DC, Vlahov D, Perlis TE, Edwards V, Friedman SR, et al. Factors associated with prevalent hepatitis C: differences among young adult injection drug users in lower and upper Manhattan, New York City. Am J Public Health 2001;91(1):23-30.

30. Dore GJ, Law M, MacDonald M, Kaldor JM. Epidemiology of hepatitis C virus infection in Australia. J Clin Virol 2003;26(2):171-84.

31. VIH/sida en Suisse: données au 31.12.2007. Bulletin OFSP 2008;6:85-6.

This article was published on 22 May 2008

Citation style for this article: Dubois-Arber F, Balthasar H, Huissoud T, Zobel F, Arnaud $S$, Samitca S, Jeannin A, Schnoz D, Gervasoni JP. Trends in drug consumption and risk of transmission of HIV and hepatitis $C$ virus among injecting drug users in Switzerland, 1993-2006. Euro Surveill. 2008;13(21):pii=18881. Available online: http:// www.eurosurveillance.org/ViewArticle.aspx?ArticleId=18881 